ZUMJ-2101-2067 (R1)

DOI 10.21608/zumj.2021.55790.2067

ORIGINAL ARTICLE.

\title{
All-in-One Technique versus Lichtenstein Technique for Inguinal Hernia Repair: Comparative Study
}

Authors and affiliation:

1- Abd-Elrahman M. Metwalli: MD in General Surgery. Department of General Surgery, Faculty of Medicine, Zagazig University, Zagazig, Egypt.

2- Tamer Mohamed Elshahidy: MD in General Surgery. Department of General Surgery, Faculty of Medicine, Zagazig University, Zagazig, Egypt.

3- Yasser A. Orban: MD in General Surgery. Department of General Surgery, Faculty of Medicine, Zagazig University, Zagazig, Egypt.

\section{Coresponding Author:}

Yasser A. Orban, MD, lecturer of Surgery, Faculty of Medicine, Zagazig University, Egypt. E-mail address:

yasser_ali_orban@yahoo.com

$\begin{array}{ll}\text { Submit Date } & 2021-01-01 \\ \text { Revise Date } & 2021-02-06 \\ \text { Accept Date } & 2021-02-17\end{array}$

\section{ABSTRACT}

Background: Chronic inguinodynia is considered the most disabling complications post-inguinal hernia repair. A novel technique (All-in-One Mesh Hernioplasty) is viable for whole cases of the primary inguinal hernia which utilizes a smaller pre-cut mesh covering whole weak regions of the inguinal canal and is wrapped by a fibro-cremasteric sheath to avoid contact between the prosthesis with neural structures. The present study aimed to compare the outcomes of the Lichtenstein technique and the All-in-One Mesh Hernioplasty technique.

Methods: A randomized clinical trial was conducted on $\wedge_{0}$ patients with a primary inguinal hernia in the department of General Surgery, Zagazig University Hospitals, Egypt from January 2018 to January 2020. The patients were categorized equally into 2 groups; Group A involving 40 patients repaired by Lichtenstein technique and Group B involving 40 patients repaired by Allin-One Mesh Hernioplast technique.

Results: There was no significant variation $(\mathrm{P}>0.05)$ among the two groups concerning demographic and clinical presentation. There was no significant variation $(\mathrm{P}>0.05)$ among them as regard wound hematoma, infection, seroma, scrotal edema, urine retention. Chronic groin pain, persistent numbness, and foreign body sensation were less in group B than group A and this variation was statistically significant $(\mathrm{P}=0.003)$, while there was no significant variation (P> 0.05) between them in hospital stay, time of return to work or normal activity, and mean postoperative follow-up.

Conclusions: All-in-One Mesh hernioplasty is a safe and effective technique in repairing the primary inguinal hernia with less postoperative chronic inguinal pain.

Keywords: Inguinal Hernia, Lichtenstein, All-in-One Mesh Hernioplasty.

\section{INTRODUCTION}

T The inguinal hernia appears as a swell in the groin that can cause discomfort and pain. If the bowel incarcerates, therefore, the strangulates may threaten life (1). Inguinal hernia is one of the most popular troublesome mesh-based repairs (2).

The important advancement was made by Lichtenstein in 1986. He clarified the tensionfree repair employing polypropylene mesh for posterior wall reinforcement of the inguinal 
canal to conquer the problem not to close it with sutures like Bassini and other techniques (3). The Lichtenstein technique is considered the care standard for the treatment of inguinal hernia. It is appropriate for adult patients and has low complications. It is more cost and time effective (4).

The Lichtenstein technique has an elevated risk of chronic pain which is challenging to treat $(5,6)$. Guttadauro et al. clarified that All-in-One Mesh hernioplasty can be used for primary inguinal hernia repair using a smaller pre-cut mesh covering whole weakly regions of the inguinal canal and is wrapped in a fibrocremasteric sheath, to avoid contact between the mesh and neural structures (7).

The current research aimed at comparing the result of primary inguinal hernia repair with the Lichtenstein technique and All-in-One Mesh Hernioplasty technique.

\section{PATIENTS AND METHODS}

A randomized clinical trial was performed in the period from January 2018 till January 2020 in the department of General Surgery, Zagazig University Hospitals, Egypt.

Patients with age equal to or more than 18 years old, the inguinal hernia either direct or indirect and of both sexes were involved. While patients suffered from complicated hernia (obstructed or strangulated), recurrent hernia, associated intraperitoneal pathology, pregnancy, abdominal wall infections, bleeding tendency, patients with end-organ failure, and disability to collaborate with the study requirement were excluded.

Sampling and Grouping: (sample size, type of sample, method of randomization, avoid bias)

The sample size was calculated to be (80) patients with primary inguinal hernia as a comprehensive sample and divided into two equal groups; Group A: included (40) patients repaired by Lichtenstein technique and Group B: included (40) patients repaired by All-inOne Mesh Hernioplasty technique. The sample was calculated as the estimated number of patients with primary inguinal hernia fulfilling the inclusion criteria attending to the department of General Surgery at Zagazig University hospitals was (20) per month and during the period of the study was (80) per four months.

Each patient took a number from one to eighty and randomization was done using a random table where odds numbers for Group A and even numbers for Group B to avoid bias in this study.

Eighty patients with primary inguinal hernia were involved in the study and categorized into 2 equal groups; Group A: included 40 patients repaired by Lichtenstein technique and Group B: involved 40 patients repaired by All-in-One Mesh Hernioplasty technique. The selection was done by systematic random sampling technique.

The patients were clinically assessed by taking history, systemic, and local examinations. Routine preoperative investigations as (complete blood count (CBC), coagulation profile, liver and kidney function tests, random blood sugar, electrocardiography (ECG)) for patients older than 40 years as an admission requirement in our hospital, and imaging studies (abdominal ultrasound) were done.

\section{Study method:}

Nothing by mouth was allowed for six hours before the operation. Prophylactic antibiotics (intravenous cefotaxime one gram) were given an hour before surgery.

The operation was performed under general or spinal anesthesia in a supine position. Inguinal skin incision was made in skin crease approximately two $\mathrm{cm}$ above the medial twothirds of the inguinal ligament. The subcutaneous fat and Scarpa's fascia were incised in line with skin incision and external oblique aponeurosis was incised in lines of its fibers to expose the spermatic cord. Group A (Lichtenstein tension-free hernioplasty); direct sacs of hernia were plicated, while indirect sacs were dissected from the spermatic cord and subsequently split and transfixed then the distal part was excised. Prolene mesh of $6 \times 11 \mathrm{~cm}$ was used in all cases. 
A polypropylene mesh was applied to the posterior wall of the inguinal canal and fixed in place utilizing polypropylene 2/0 (Ethicon ${ }^{\circledR}$ ). The mesh was fixed from above to the conjoint tendon and down to the inguinal ligament. The medial end of the mesh should extend medially beyond the public tubercle for $1 \mathrm{~cm}$.

Group B (All-in-One Mesh Hernioplasty) technique: a longitudinal incision was performed over the cremasteric muscle and external spermatic cord fascia (fibrous cremasteric sheath); then these were dissected from the spermatic cord to the inguinal ligament. The medial boundaries of the cremasteric sheath were grasped with Klemmer clamps, then the hernial sac was identified and dissected from the spermatic cord. The hernia sac must be dissected to its neck and freed from the deep ring to have the ability to be minimized completely into the abdominal cavity (Figure 1). Then, the deep inguinal ring was narrowed with resorbable interrupted sutures, if necessary. The polypropylene pre-cut mesh was prepared to reinforce the entire floor of the inguinal canal. It was shaped for conforming to anatomy without the danger of wrinkling or it required trimming. Section A of the mesh was utilized to encircle the spermatic cord forming a cone around them by overlapping the two tails (A1 and A2). The tails length can be shortened to fit the spermatic cord diameter. Section $\mathrm{C}$ of the mesh was designed to cover the posterior wall of the inguinal canal, transversalis fascia. The distal end of section $\mathrm{C}$ (about one $\mathrm{cm}$ ) was fixed to the pubic tubercle utilizing resorbable suture (Figures 2, 3).

The medial edge of the previously identified cremasteric muscle was retrieved and sutured to the musculoaponeurotic structures utilizing a running resorbable suture for covering the mesh. The cremaster only serves as a cover preventing the connection between the spermatic cord and the underlying mesh. If the muscle was wounded through dissection, it can be repaired with a resorbable suture. The spermatic cord was returned to its natural position (7).
In two groups, external oblique aponeurosis was closed with a continuous suture of $2 / 0$ Vicryl (Ethicon) and then subcutaneous tissue was approximated with 3/0 vicryl. Skin closure was completely utilizing Subcuticular Suture of 3/0 Polypropylene. No drain was used.

Antibiotics continued postoperatively for one week. Patients were discharged within 24 hours after the operation. Return to normal activity was permitted a week after the discharge instructions that included avoidance of straining or carrying heavy objects for three months. On the 3rd and 7th postoperative day, the follow-up visits were scheduled then two to three weeks then every three months then for one year for evaluating the postoperative complexity (postoperative pain, infection, retention of urine, hematoma, and seroma formation), chronic pain, and hernia recurrence.

The primary endpoint (outcome) was the assessment of chronic groin pain in both groups. The secondary endpoints (outcome) were perioperative parameters (operative time, intraoperative, and postoperative complexity), postoperative pain scoring, hospital stay, time to return to normal activity, and follow-up details.

Early postoperative pain intensity was evaluated through the visual analog scale (VAS) on the second post-operative day. Using a visual analog scale, the patient was instructed to point to the position on the line to indicate how much pain he/she might feel. This system is a $10 \mathrm{~cm}$ line with anchor statements on the left (no pain) and on the right (extreme pain). The patient is asked to mark their current pain level on the line. The score of the VAS was recorded by measuring the distance in centimeters (0 to 10) from the "no pain" anchor point (8).

For chronic postoperative pain, the question used to address chronic pain was question 2, extracted from the Inguinal Pain Questionnaire (IPQ), developed specifically for groin hernia repair (9). The questionnaire was applied 6 
months after surgery by telephone. Pain was graded from 1 to 7 :

Level 1 - no pain

Level 2 - pain present, but easily ignored

Level 3 - pain present, cannot be ignored, but does not interfere with everyday activities;

Level 4 - pain present, cannot be ignored and interferes with concentration on everyday activities

Level 5 - pain present, interferes with most activities

Level 6 - pain present, necessitating bed rest

Level 7 - pain present prompt medical advice sought.

Levels 1-3 were considered to indicate no pain, while levels 4-7 represent pain.

\section{Ethics approval and consent to participate:}

Official permissions were gained from the Institutional Review Board at the Faculty of Medicine, Zagazig University Hospitals, and from the General Surgery department at the same University. The study was done according to The Code of Ethics of the World Medical Association (Declaration of Helsinki) for studies involving humans. Written informed consent was obtained from all patients and they had the right to withdraw from the study at any time and without negatively affecting their medical care. The study results could be utilized as a scientific publication, but the identity of the participant will be confidential.

\section{Statistical analysis:}

The collected data were analyzed utilizing the Statistical Package for Social Science (SPSS) (Version 20.0. Armonk, NY: IBM Corp). Continuous variables with a normal distribution were announced as mean and standard deviation (SD). Categorical variables were abstracted as frequencies and percentages. Quantitative data was estimated utilizing independent t-test which was suitable for normally distributed data, while qualitative data was evaluated by Chi-square test $(\chi 2)$ or Fisher exact test. $\mathrm{P}$ values $\leq 0.05^{*}$ and $\leq 0.001^{* *}$ were considered statistically significant and highly statistically significant respectively.

\section{RESULTS}

Eighty patients with primary inguinal hernia were involved and divided into 40 patients in Group A (Lichtenstein tension-free hernioplasty) and 40 patients in Group B (Allin-One Mesh Hernioplasty) with no significant variation $(\mathrm{P}>0.05)$ among them concerning socio-demographic (sex, age, smoking) and clinical presentation (Body mass index; BMI), American Society of Anesthesiologists (ASA) physical status, type and side of hernia), and there was no significant variation $(\mathrm{P}>0.05)$ among them as concern type of preoperative comorbidity; ensuring comparability of both groups. The mean age of Group A was $44.3 \pm 6.5$ years, while the mean age for Group B was $42.2 \pm 4.6$ years. More than half of both groups were males with a mean BMI were $31.4 \pm 0.97$ and $31.1 \pm 0.85 \mathrm{~kg} / \mathrm{m} 2$ in Group A and $\mathrm{B}$. Indirect, direct, and pantaloon hernia were the types of hernia included in this study and the most popular type was indirect hernia in both Group A and B with percent (67.5\%) and (72.5\%) respectively (Table $\mathbf{1}$ ).

Regarding the intraoperative characteristics, there was no statistically significant variation (P> 0.05) among Group A and B in operative time with a mean of $43.2 \pm 0.75$ minute and $42.9 \pm 0.67$ minute respectively. Furthermore, there was no significant variation $(\mathrm{P}>0.05)$ among them as concern type of anesthesia, wherever, more than two-thirds of them had spinal anesthesia (Table 2).

On comparing the early postoperative complications, there was no significant variation ( $P>0.05$ ) between both groups concerning wound infection, wound seroma, wound hematoma, urine retention, and scrotal edema (Table 3). Early postoperative pain in this study was mild pain in both groups with a mean Visual Analog Scale (VAS) score $(3.21 \pm 0.88$ vs $2.89 \pm 0.73)$ at the first postoperative day in Group A, B respectively (Table 3).

This study showed that the chronic groin pain was less in Group B when compared with Group $\mathrm{A}$ and this difference was statistically significant $(\mathrm{P}=0.003)$ (Table 4).. 
The outcome of both techniques in (Table 5) clarified that there was no statistically concern mean hospital stay, returning to normal significant variation $(\mathrm{P}>0.05)$ between them as Table (1): Socio demographic and clinical presentation of the studied groups $(n=80)$.

\begin{tabular}{|c|c|c|c|}
\hline Characteristics & Group A $(n=40)$ & Group B $(n=40)$ & P value \\
\hline Age (years) mean \pm SD & $44.3 \pm 6.5$ & $42.2 \pm 4.6$ & ${ }^{\mathrm{a}} 0.099$ \\
\hline $\begin{array}{l}\text { Sex No }(\%) \\
\text { Male } \\
\text { Female }\end{array}$ & $\begin{array}{l}30(75 \%) \\
10(25 \%)\end{array}$ & $\begin{array}{c}33(82.5 \%) \\
7(17.5 \%)\end{array}$ & ${ }^{\mathrm{b}} 0.412$ \\
\hline BMI $\left(\mathrm{Kg} / \mathrm{m}^{2}\right)$ mean \pm SD & $31.4 \pm 0.97$ & $31.1 \pm 0.85$ & ${ }^{\mathrm{a}} 0.145$ \\
\hline $\begin{array}{l}\text { Smoking No }(\%) \\
\text { Yes } \\
\text { No }\end{array}$ & $\begin{array}{l}16(40 \%) \\
24(60 \%)\end{array}$ & $\begin{array}{l}12(30 \%) \\
28(70 \%)\end{array}$ & ${ }^{\mathrm{b}} 0.348$ \\
\hline $\begin{array}{l}\text { Comorbidity No }(\%) \\
\text { No } \\
\text { DM } \\
\text { COPD }\end{array}$ & $\begin{array}{l}32(80 \%) \\
3(7.5 \%) \\
5(12.5 \%)\end{array}$ & $\begin{array}{c}31(77.5 \%) \\
6(15 \%) \\
3(7.5 \%)\end{array}$ & ${ }^{\mathrm{b}} 0.468$ \\
\hline $\begin{array}{l}\text { ASA Physical Status No }(\%) \\
\text { I } \\
\text { II }\end{array}$ & $\begin{array}{l}28(70 \%) \\
12(30 \%)\end{array}$ & $\begin{array}{l}30(75 \%) \\
10(25 \%)\end{array}$ & ${ }^{\mathrm{b}} 0.617$ \\
\hline $\begin{array}{l}\text { Type of Hernia No } \\
\text { Indirect } \\
\text { Direct } \\
\text { Pantaloon }\end{array}$ & $\begin{array}{c}27(67.5 \%) \\
9(22.5 \%) \\
4(10 \%)\end{array}$ & $\begin{array}{l}29(72.5 \%) \\
6 \quad(15 \%) \\
5(12.5 \%)\end{array}$ & ${ }^{\mathrm{b}} 0.676$ \\
\hline $\begin{array}{l}\text { Side of Hernia No } \quad(\%) \\
\text { Right side } \\
\text { Left side }\end{array}$ & $\begin{array}{l}25(62.5 \%) \\
15(37.5 \%)\end{array}$ & $\begin{array}{l}28(70 \%) \\
12(30 \%)\end{array}$ & b0.478 \\
\hline
\end{tabular}

$\mathrm{BMI}=$ Body Mass Index, $\mathrm{DM}=$ Diabetes mellitus, $\mathrm{COPD}=$ Chronic obstructive pulmonary disease, $\mathrm{ASA}=\mathrm{American}$ Society of Anesthesiologists, $\mathrm{SD}=$ Standard deviation, ${ }^{\mathrm{a}}$ Independent $\mathrm{t}$ test, ${ }^{\mathrm{b}}$ Chi square test (X2)

Table (2): Intraoperative characteristics of the studied groups $(\mathbf{n}=\mathbf{8 0})$.

\begin{tabular}{|c|c|c|c|}
\hline Characteristics & Group A $(n=40)$ & Group B $(n=40)$ & P value \\
\hline $\begin{array}{l}\text { Type of anesthesia No } \\
\text { Spinal } \\
\text { General }\end{array}$ & $\begin{array}{c}32(80 \%) \\
8(20 \%)\end{array}$ & $\begin{array}{c}35(87.5 \%) \\
5(12.5 \%)\end{array}$ & ${ }^{\mathrm{a}} 0.363$ \\
\hline Operative time (min) mean \pm SD & $43.2 \pm 0.75$ & $42.9 \pm 0.67$ & ${ }^{b} 0.063$ \\
\hline
\end{tabular}


Table (3): Early Postoperative complications among the studied groups $(n=80)$.

\begin{tabular}{|c|c|c|c|}
\hline Complications & $\begin{array}{c}\text { Group A }(\mathrm{n}=40) \\
\text { No }(\%)\end{array}$ & $\begin{array}{c}\text { Group B }(n=40) \\
\text { No }(\%)\end{array}$ & P value \\
\hline $\begin{array}{l}\text { Wound hematoma } \\
\text { Yes } \\
\text { No }\end{array}$ & $\begin{aligned} 1 & (2.5 \%) \\
39 & (97.5 \%)\end{aligned}$ & $\begin{aligned} 1 & (2.5 \%) \\
39 & (97.5 \%)\end{aligned}$ & 1.00 \\
\hline $\begin{array}{l}\text { Wound infection } \\
\text { Yes } \\
\text { No }\end{array}$ & $\begin{array}{cc}2 & (5.0 \%) \\
38 & (95.0 \%)\end{array}$ & $\begin{aligned} 1 & (2.5 \%) \\
39 & (97.5 \%)\end{aligned}$ & 0.556 \\
\hline $\begin{array}{l}\text { Wound seroma } \\
\text { Yes } \\
\text { No }\end{array}$ & $\begin{array}{cc}3 & (7.5 \%) \\
37 & (92.5 \%)\end{array}$ & $\begin{aligned} 1 & (2.5 \%) \\
39 & (97.5 \%)\end{aligned}$ & 0.305 \\
\hline $\begin{array}{l}\text { Scrotal edema } \\
\text { Yes } \\
\text { No }\end{array}$ & $\begin{array}{cc}3 & (7.5 \%) \\
37 & (92.5 \%)\end{array}$ & $\begin{array}{cl}2 & (5.0 \%) \\
38 & (95.0 \%)\end{array}$ & 0.644 \\
\hline $\begin{array}{l}\text { Urine retention } \\
\text { Yes } \\
\text { No } \\
\quad \text { VAS score mean } \pm \text { SD }\end{array}$ & $\begin{array}{cc}2 & (5.0 \%) \\
38 & (95.0 \%) \\
3.21 \pm 0.88\end{array}$ & $\begin{array}{cc}5 & (12.5 \%) \\
35 & (87.5 \%) \\
2.89 \pm 0.73\end{array}$ & $\begin{array}{l}0.235 \\
{ }^{\mathrm{b}} 0.081\end{array}$ \\
\hline
\end{tabular}

${ }^{a}$ Fisher exact test

$\mathrm{SD}=$ Standard deviation, VAS $=$ Visual Analog Scale, ${ }^{\mathrm{b}}$ Independent $\mathrm{t}$ test

Table (4): Late postoperative complications among the studied groups $(\mathrm{n}=\mathbf{8 0})$.

\begin{tabular}{|c|c|c|c|}
\hline Complications & Group A $(n=4,0)$ & Group B $(n=40)$ & a value \\
\hline & $(\%)$ & $(\%)$ & \\
\hline $\begin{array}{l}\text { Chronic groin pain } \\
\text { Yes } \\
\text { No }\end{array}$ & $\begin{array}{ll}12 & (30.0 \%) \\
28 & (70.0 \%)\end{array}$ & $\begin{aligned} 1 & (2.5 \%) \\
39 & (97.5 \%)\end{aligned}$ & 0.003 \\
\hline
\end{tabular}

${ }^{\mathrm{a}}$ Fisher exact test

Table (5): Outcome among the studied groups $(n=80)$.

\begin{tabular}{|c|c|c|c|}
\hline Outcome & $\begin{array}{c}\text { Group A }(n=40) \\
\text { mean } \pm \text { SD }\end{array}$ & $\begin{array}{c}\text { Group B }(n=40) \\
\text { mean } \pm \text { SD }\end{array}$ & P value \\
\hline Hospital stay (day) & $1.04 \pm 0.21$ & $1.12 \pm 0.37$ & 0.238 \\
\hline Return to work or normal activity(days) & $7.60 \pm 0.13$ & $7.37 \pm 2.62$ & 0.581 \\
\hline Mean postoperative follow-up (months) & $24.00 \pm 0.85$ & $23.71 \pm 0.78$ & 0.116 \\
\hline
\end{tabular}

$\mathrm{SD}=$ Standard deviation, $\quad{ }^{\mathrm{a}}$ Independent $\mathrm{t}$ test 


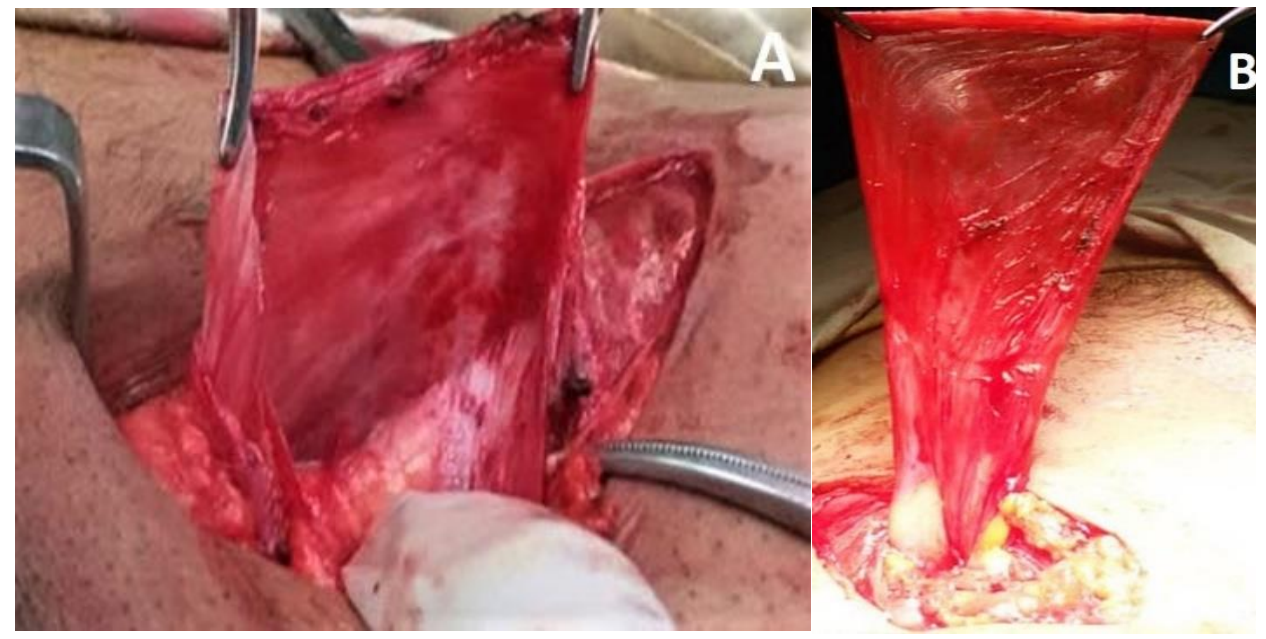

Figure 1: All-in-One Mesh Hernioplasty. A: fibrous cremasteric sheath. B: hernia sac.
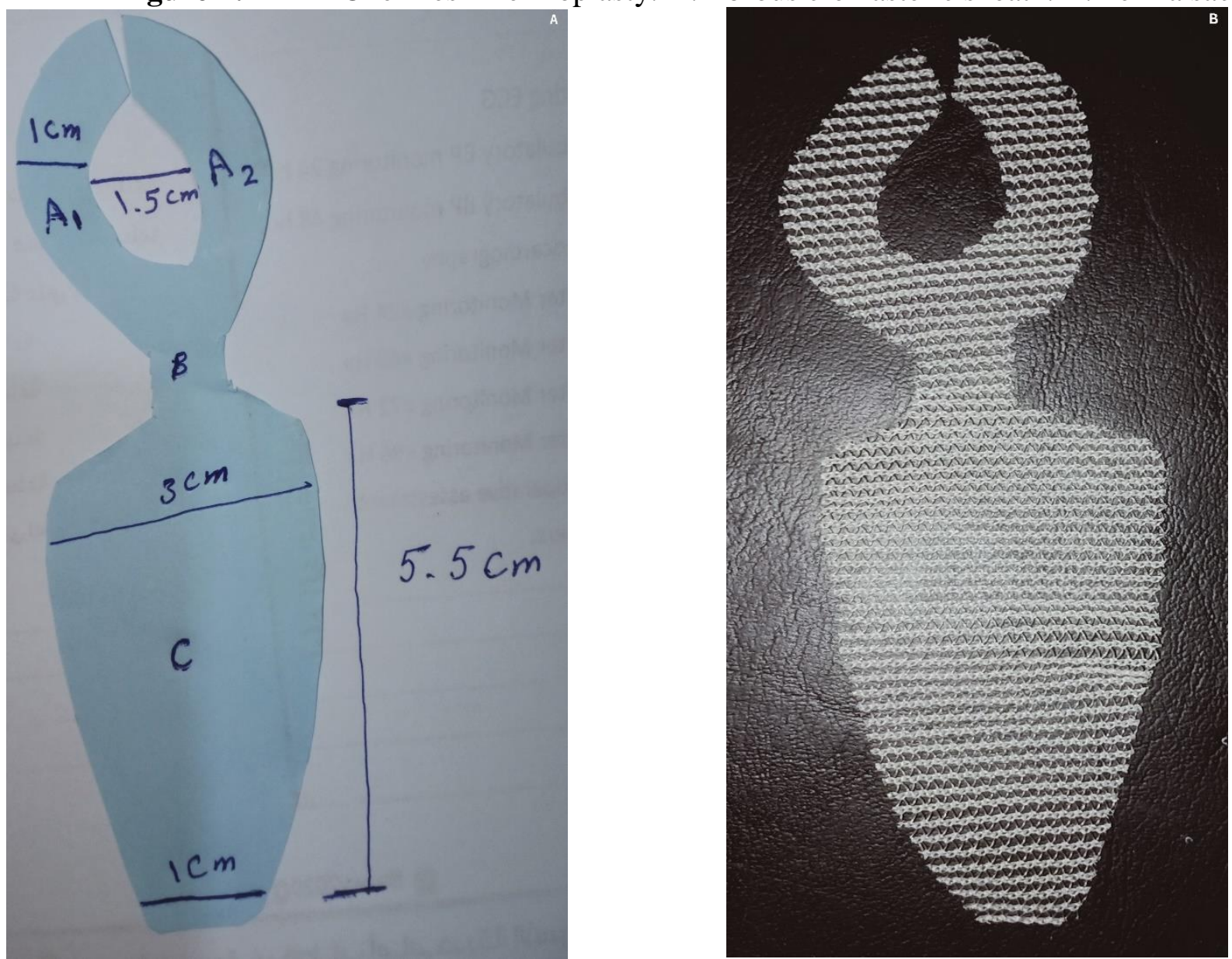

Figure 2: the design of the precut mesh, A: the design and dimensions of the precut mesh using a paper sheet, B: the precut mesh. 

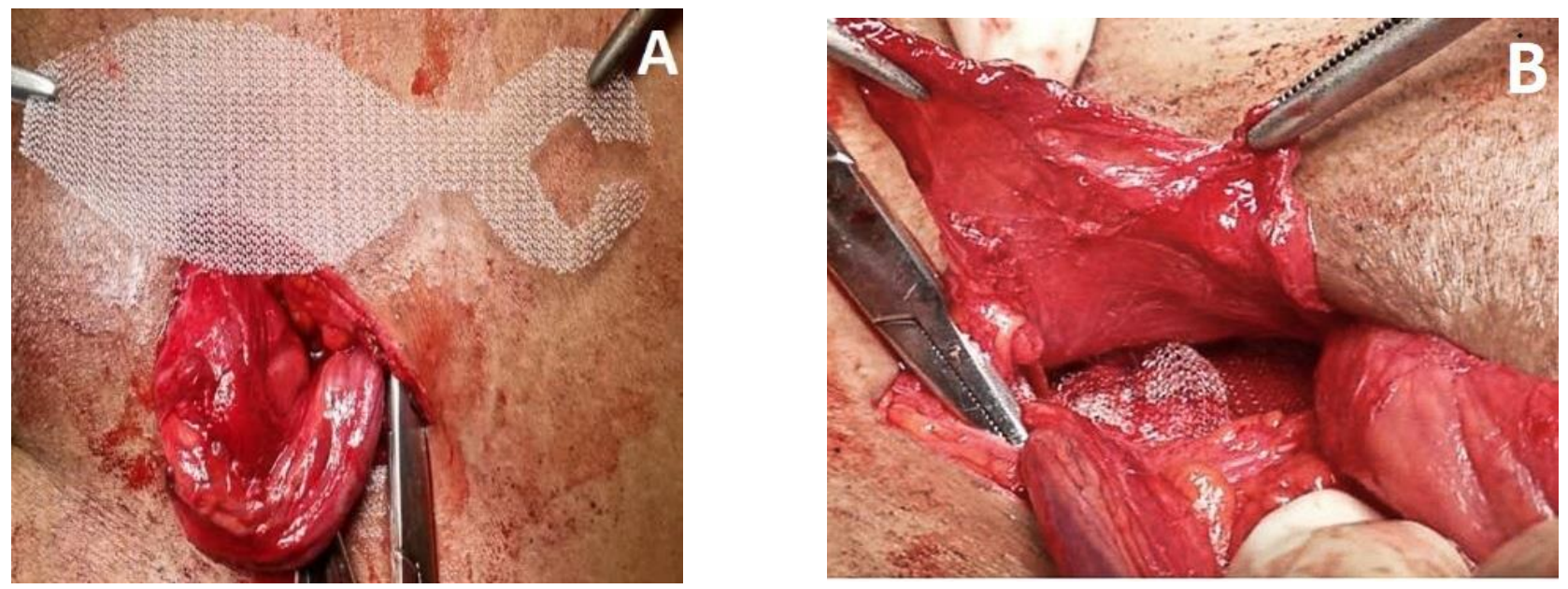

Figure 3: Polypropylene pre-cut mesh reinforces the floor of the inguinal canal.

\section{DISCUSSION}

Repairing of inguinal hernia is considered the most popular (10-15\%) surgical approaches done all over the world. From Bassini's repair in 1887 , many operative techniques have been announced, however yet no eventual operative technique is believed the best (10).

Surgeons are searching for the optimal mesh and location and method of placement. Currently, there are 2 methods that masterful, the first one, the Lichtenstein repair, being the open anterior approach, and the other, laparoscopic repairing, being the posterior approach (11). Chronic inguinodynia is considered one of the most disabling complexities post inguinal hernia repair so, it can adversely influence the daily life of up to $10 \%$ of patients (12).

The accurate reason for pain is still unobvious and different etiologies have been suggested, involving suture materials, type of mesh, and tissue handling techniques. It is very serious to realize chronic groin pain that happening post 3 months post-operative after herniorrhaphy and this should not be disorganized directly postoperative pain (13). It may be secondary to nerve entrapment or stretching, inflammation, fibrotic reactions, or neuroma formation and may require many interventions involving oral analgesia, local anesthetic injections, physiotherapy, or further surgery (14).
The procedure qualified in this study is viable to all the primary inguinal hernia situations. It utilizes the standard of coverage of the mesh with fibro-cremasteric sheath to insulate the mesh, preventing its contact with the canal contents, especially the nerves. The procedure purpose to minimize the occurrence of chronic neuralgia which generates chronic pain, discomfort, disturbance, and sometimes disabling pain.

Regarding socio-demographic data (age, sex, and smoking) of the included groups in the current study, no significant variation was present among them with the mean age of Group A was $44.3 \pm 6.5$ years, while the mean age for Group B was $42.2 \pm 4.6$ years. The study was conducted on 63 males $(78.75 \%)$ and 17 females $(21.25 \%)$. Similarly, a study by Esteban et al., which was conducted on 90 patients with a primary inguinal hernia; 79 males $(87.7 \%)$ and 11 females $(12.3 \%)$. The age distribution ranged from 19 to 83 years with a mean was 49 years (15). Shivhare et al. studied 96 patients who presented with primary inguinal hernia (95 males $(98.96 \%)$ and one female $(1.04 \%)$ ), and their age distribution ranged from 24 to 68 years with a mean of 46 years (16). Guttadauro et al. conducted a study of 250 adult patients with primary inguinal hernia treated with All In One Mesh Hernioplasty, 241 males (96.4\%) and 9 females (3.6\%) with an average mean age of 61.7 years 
(range: 22-90) (7). Also, the study of Khyrallh, carried out on 100 male patients who suffered from a primary inguinal hernia and their age distribution ranged from 20 to 60 years with a mean of 48.6 years (3).

This study included nine diabetic patients (11.25\%), eight patients (10\%) presented with chronic obstructive pulmonary disease (COPD), and 28 patients $(35 \%)$ were smokers with no significant variation among both groups. This was in the same line with Esteban et al., who included 14 patients $(15.5 \%)$, and 9 patients (10\%) presented with DM and COPD and 38 patients (42.2\%) were smokers (15) and also similar to the study of Khyrallh, which conducted on 16 patients (16\%), and 13 patients (13\%) presented with DM and chronic respiratory disease and 48 patients $(48 \%)$ were smokers (3).

The study at hand involved 56 patients (70\%) presented with an indirect hernia, 15 patients (18.75\%) presented with a direct hernia, and 9 patients $(11.25 \%)$ presented with pantaloon hernia and the right side inguinal hernia was found among 53 patients $(66.25 \%)$ that were the commonest type in both groups. This agreed with Khyrallh who included 79 patients $(79 \%)$ with an indirect hernia, seven patients (7\%) with a direct hernia and 14 patients (14\%) with pantaloon hernia, and 51 patients $(51 \%)$ with right side inguinal hernia that was the commonest type (3), also similar to the study of Azher et al., in which 60 patients (60\%) presented with an indirect hernia, 40 patients (40\%) with a direct hernia, and the right side inguinal hernia in 65 patients $(65 \%)$ which was the commonest type (17). The study conducted by Esteban et al. showed that 57 patients $(63.3 \%)$ presented with an indirect hernia, 32 patients $(35.6 \%)$ with a direct hernia and one patient $(1 \%)$ with pantaloon hernia, and the left side inguinal hernia among 47 patients $(52.2 \%)$ which was the most common type (15).

This present study exhibited that there was no significant variation concerning the mean operative time as cases of Group A and Group $B$ had mean operative time $43.2 \pm 0.75$ minute and 42.9 \pm 0.67 minute respectively. On comparing with other previous studies; Guttadauro et al. recorded that the mean operative time using (All-in-One Mesh Hernioplasty) was 25 minutes (7). Khyrallh reported that the mean operative time using the (Lichtenstein tension-free hernioplasty) was 41.6 \pm 4.2 minutes (3). Ibrahim noted that the duration of surgery in the group of patients using Lichtenstein hernioplasty (mean $51.3 \pm 10.6$ minutes, range 49-72) was significantly shorter than using the modified technique Hernioplasty with fibrocremasteric sheath (mean 58.4 \pm 9.2 minute, range 54-81) (18). Shivhare et al., (16) and Munghate et al., (19) observed that the mean operative time utilizing Lichtenstein hernioplasty was 74 minutes. Abu Ella and El Atrebi (20), described that the mean operative time utilizing Lichtenstein hernioplasty was $65 \pm 16.2$ minute. In this study, there was no significant variation among both groups concerning postoperative complexities (wound infection, wound hematoma, scrotal edema, wound seroma, and urine retention). There were two small hematomas, one $(2.5 \%)$ in each group and four postoperative seroma; Group A included three cases $(7.5 \%)$ while Group B included one case $(2.5 \%)$. All cases were resolved in three weeks with conservative management. Postoperative wound infection occurred only in two cases $(5 \%)$ in Group A and one case $(2.5 \%)$ in Group $B$ associated with superficial postoperative wound infection and the infections were successfully treated with antibiotics. Also, there were five cases of scrotal edema, Group A included three cases $(7.5 \%)$ while Group B included two cases $(5.0 \%)$ and postoperative urine retention, Group A included two cases (5.0\%) while Group B included five cases $(12.5 \%)$.

The above-mentioned findings were supported with other researches; Ibrahim (18), found in group A (the modified technique Hernioplasty with fibrocremasteric sheath) two patients (4.4\%) complained of urinary retention, six patients $(13.3 \%)$ complained of seroma, two 
patients $(4.4 \%)$ complained of hematoma, two patients $(4.4 \%)$ complained of wound infection, five patients (11\%) complained of scrotal edema and bruising, and one patient (2\%) complained of orchitis, while in group B (Lichtenstein repair) two patients (4.4\%) complained of urinary retention, seven patients $(15.5 \%)$ complained of seroma, one patient (2\%) complained of hematoma, three patients $(6.5 \%)$ complained of wound infection, three patients $(6.5 \%)$ complained of scrotal edema and bruising, and no patients complained of orchitis with no statistically significant differences between them.

Guttadauro et al., clarified postoperative complexities post utilizing (All-in-One Mesh Hernioplasty) as following; 3 patients (1.2\%) with urinary retention, 2 patients $(0.8 \%)$ with orchitis, and 14 cases $(5.6 \%)$ had bruising of the external genitalia(7). Azher A et al. clarified postoperative complexities post-Lichtenstein hernioplasty. Five (5\%) patients had wound infection, 12 (12\%) patients had seroma, seven (7\%) patients had hematoma, and five (5\%) patients had urinary retention(17). Munghate A et al., recorded after Lichtenstein hernioplasty, four (8\%), 12 (24\%), six (12\%), and two (4\%) patients complained of urinary retention, wound infection, seroma, and scrotal edema respectively (19). Khyrallh, found, after Lichtenstein hernioplasty, one $(2 \%)$, one $(2 \%)$, two $(4 \%)$, two (4\%), and one (2\%) patients complained of urinary retention, hematoma, wound infection, seroma, and testicular swelling respectively (3).

Early Postoperative pain in this study was mild pain in both groups with a mean VAS score $(3.21 \pm 0.88$ vs $2.89 \pm 0.73)$ at the first postoperative day in Group A, B respectively, and diminished thereafter. There were 16 cases $(40 \%)$ in Group A and 12 cases (30\%) in Group $\mathrm{B}$ required no postoperative analgesics while the remaining patients required non-steroidal analgesics (mild or moderate postoperative analgesics as paracetamol, co-codamol, or ibuprofen for 3 to 5 days) with no significant variation among both groups.
In accordance with the study of Ibrahim, who found that the mean VAS score at first postoperative day was 3.9 and 4.1 in groups A and $\mathrm{B}$ that diminished thereafter, and he record $17(37.7 \%)$ patients in group A and $15(33.3 \%)$ patients in group B required no analgesics (18). Guttadauro et al. also recorded a slight immediate postoperative period (mean VAS score was 2.1$)$ and 79 patients $(31.6 \%)$ did not need any postoperative analgesia in the hospital or any subsequent analgesia at home, while the remaining 171 (68.4\%) were given non-narcotic analgesics (7). Additionally, Testa et al. clarified only weak postoperative pain in most of the patients at discharge and $31.7 \%$ of them were fully painless performed the All In One Mesh Hernioplasty procedure on 400 patient presented with primary unilateral inguinal (21). Khyrallh, found that (62\%) patients needed analgesic more than three doses after Lichtenstein hernioplasty (3).

The present study showed that chronic groin pain was more in Group A, 12 cases (30.0\%), than in Group B, one case $(2.5 \%)$, and this variation was highly significant statistically, besides, postoperative continual numbness in this study clarified there was highly significant variation statistically among both groups where 13 cases $(32.5 \%)$ in Group A and one case $(2.5 \%)$ in Group B. These findings can be explained by the utilize of a smaller quantity of prosthetic material allows the envelopment of the mesh by the fibrocremasteric sheath to avoid contacting with the surrounding nerves that don't need the dissection or identification of any nervous structure present under the aponeurosis. The ilioinguinal nerve is adherent to the outer surface of the cremaster in its more lateral part and the iliohypogastric nerve runs medially on the internal oblique muscle. The nerve structures do not contact with the site of mesh (7).

In matching with Ibrahim, who found that chronic groin pain and discomfort at 18 months was more in Group B (Lichtenstein repair) five cases $(11.0 \%)$ than in Group A (The modified technique Hernioplasty with fibrocremasteric 
sheath) two cases (4.4\%) and the variation was significant statistically (18). However, Guttadauro et al., (7) and Testa et al., (21) didn't observe any case of postoperative neuralgia post All in One Mesh Hernioplasty after follow-up for 24 months. Regarding, foreign body sensibility in this study, there was highly significant statistical variation among both groups where 15 cases $(37.5 \%)$ in Group A and one case $(2.5 \%)$ in Group B. Also, Guttadauro et al didn't record any case of postoperative foreign body sensation or even simply discomfort after All In One Mesh Hernioplasty after 24 months follow up (7).

In the current study, all cases were discharged on the first postoperative day except 2 cases $(5.0 \%)$ in Group A and one case $(2.5 \%)$ in Group B correlated with postoperative wound infection was discharged on the third day postoperatively. The mean time of return to work or normal activity in Group A, B was $(7.60 \pm 0.13$ vs $7.37 \pm 2.62)$ days and the postoperative follow-up in both groups was 24 months with no statistically significant difference in both groups. Guttadauro et al. recorded $23(9.2 \%)$ subjects experienced slight limitations of normal activities through the $1^{\text {st }}$ week. $30(20.1 \%)$ patients could engage in sports one week from surgery, while 46 (30.9\%) began between seven and 21 days after surgery. The average follow-up was 15 months (7). However, Testa et al., reported that all patients were discharged within three hours after surgery and $(91 \%)$ of patients returned to their normal daily activities within two to three days after surgery and the postoperative followup was 24 months with no statistically significant variation in both groups after All In One Mesh Hernioplasty procedure (21). Ibrahim observed that the mean hospital stay in group A was $1 \pm 0.4$ days and in group B was $1.2 \pm 0.6$ day.

The mean time of return to work or normal activity in Group A, B was $(9.1 \pm 3.4,10.2 \pm 4.6)$ and the postoperative follow-up in both groups was 18 months with no statistically significant difference in both groups (7). Khyrallh, reported that the mean hospital stay was $1.3 \pm 0.63$ days and the mean time to return to work or normal activity was $10.8 \pm 7.4$ days after Lichtenstein hernioplasty procedure (3).

\section{LIMITATIONS}

This study had some limitations that included relatively small sample size, single place, and the data couldn't be generalized as the study design institutional-based and not communitybased. Another limitation of the present study was that the relatively short follow up period.

\section{CONCLUSIONS}

All-in-One Mesh Hernioplasty is a safe and effective technique in repairing primary inguinal hernia with less postoperative longterm complications (Chronic groin pain, Persistent numbness, and Foreign body sensation) as the prosthetic mesh was not in contact with nerves and cord and better outcomes (better patient compliance and satisfaction) as compared with the classic Lichtenstein procedure.

\section{Funding}

The authors received no financial support for the research, authorship, and/or publication of this article.

Competing interests: The authors declare that they have no competing interests.

\section{REFERENCES}

1. Willaert W, Bacquer D De, Rogiers X, Troisi R, Berrevoet F. Open Preperitoneal Techniques versus Lichtenstein Repair for elective Inguinal Hernias. Cochrane Database Syst Rev [Internet]. 2012 Jul; Available from: https://doi.org/10.1002\%2F14651858.cd008034. pub2

2. Khan HM, Ramesh BS, Bobburi V. Tension free, mesh free inguinal hernia repair: a prospective study of Desarda's technique. Int Surg J [Internet]. 2020 Mar;7(4):1116. Available from: doi:10.21608/aimj.2020.23116.1116.

3. Khyrallh A. Lichtenstein procedure versus darn repair in primary inguinal hernia surgery. AlAzhar Assiut Med J [Internet]. 2017;15(4):196. Available from: https://doi.org/10.4103\%2Fazmj.azmj_59_17

4. Vupputuri H, Kumar Rs, Subramani P, Venugopal K. A single-blind, randomized controlled study to compare Desarda technique 
with Lichtenstein technique by evaluating shortand long-term outcomes after 3 years of followup in primary inguinal hernias. Int $\mathbf{J}$ Abdom Wall Hernia Surg [Internet]. 2019;2(1):16. Available from: https://doi.org/10.4103\%2Fijawhs.ijawhs_21_18

5. Rosenberg J, Andresen K. The Onstep Method for Inguinal Hernia Repair: Operative Technique and Technical Tips. Surg Res Pract [Internet]. 2016;2016:1-7. Available from: https://doi.org/10.1155\%2F2016\%2F6935167

6. Chen DC, Hiatt JR, Amid PK. Operative Management of Refractory Neuropathic Inguinodynia by a Laparoscopic Retroperitoneal Approach. \{JAMA\} Surg [Internet]. 2013 Oct;148(10):962. Available from: https://doi.org/10.1001\%2Fjamasurg.2013.3189

7. Guttadauro A, Maternini M, Frassani S, Simone $M$ De, Chiarelli M, Macchini $D$, et al. \{ltextquotedblleft $\}$ All-in-one mesh\{\textquotedblright\} hernioplasty: A new procedure for primary inguinal hernia open repair. Asian J Surg [Internet]. 2018 Sep;41(5):473-9. Available from: https://doi.org/10.1016\%2Fj.asjsur.2017.07.003

8. Halfaker DA, Akeson ST, Hathcock DR, Mattson C, Wunderlich TL. 3 - Psychological Aspects of Pain. In: Lennard TA, Walkowski S, Singla AK, Vivian DGBT-PP in CP (Third E, editors. Saint Louis: Hanley \& Belfus; 2011. p. 13-22. Available from: https://www.sciencedirect.com/science/article/pii /B978141603779810003X

9. Fränneby U, Gunnarsson $U$, Andersson $M$, Heuman R, Nordin P, Nyrén O, et al. Validation of an Inguinal Pain Questionnaire for assessment of chronic pain after groin hernia repair. $\mathrm{Br} \mathrm{J}$ Surg. 2008;95(4):488-93.

10. Eker HH. Randomized Clinical Trial of Total Extraperitoneal Inguinal Hernioplasty vs Lichtenstein Repair. Arch Surg [Internet]. 2012 Mar;147(3):256. Available from: https://doi.org/10.1001\%2Farchsurg.2011.2023

11. Miserez M, Peeters E, Aufenacker T, Bouillot JL, Campanelli G, Conze J, et al. Update with level 1 studies of the European Hernia Society guidelines on the treatment of inguinal hernia in adult patients. Hernia [Internet]. 2014 Mar;18(2):151-63. Available from: https://doi.org/10.1007\%2Fs10029-014$1236-6$
12. Charalambous MP, Charalambous CP. Incidence of chronic groin pain following open mesh inguinal hernia repair, and effect of elective division of the ilioinguinal nerve: metaanalysis of randomized controlled trials. Hernia [Internet]. 2018 Mar;22(3):401-9. Available from: https://doi.org/10.1007\%2Fs10029-0181753-9

13. Hakeem A. Inguinodynia following Lichtenstein tension-free hernia repair: A review. World $\mathrm{J}$ Gastroenterol [Internet]. 2011;17(14):1791. Available from: https://doi.org/10.3748\%2Fwjg.v17.i14.1791

14. Dittrick GW, Ridl K, Kuhn JA, McCarty TM. Routine ilioinguinal nerve excision in inguinal hernia repairs. Am J Surg [Internet]. 2004 Dec;188(6):736-40. Available from: https://doi.org/10.1016\%2Fj.amjsurg.2004.08.03 9

15. Esteban MB, Pallarés MC, de Rojas EAS, Vila MJ. Prospective Randomized Trial of LongTerm Results of Inguinal Hernia Repair Using Autoadhesive Mesh Compared to Classic Lichtenstein Technique With Sutures and Polypropylene Mesh. Cirug $\left\{\backslash^{\prime}\{\backslash \mathrm{i}\}\right\}$ a Española (English Ed [Internet]. 2014 Mar;92(3):195-200. Available from: https://doi.org/10.1016\%2Fj.cireng.2013.03.006

16. Shivhare P, Dugg P, Mittal S, Singh H, Kumar A. A Prospective Randomized Study Comparing Skin Staples and Polypropylene Sutures for Securing the Mesh in Lichtenstein \{ltextquotesingle\}s Repair. Arch Clin Exp Surg [Internet]. 2014;3(3):147. Available from: https://doi.org/10.5455\%2Faces.2013112102372 3

17. Azher A, Ghafoor A, Hanif Z. Evaluation of the efficacy of lichtenstein mesh hernioplasy and its complications. INDO Am J Pharm Sci. 2018;5(12):13934-8.

18. Ibrahim A. A modified technique of lichtenstein repair using fibro-cremasteric sheath to cover the mesh versus traditional Lichtenstein hernioplasty: a comparative study. Sci J AlAzhar Med Fac Girls [Internet]. 2019;3(2):437. Available from: https://doi.org/10.4103\%2Fsjamf.sjamf_52_19

19. Munghate A, Mittal S, Singh H, Singh G, Yadav M. Skin Staples: A Safe Technique for Securing Mesh in Lichtensteins Hernioplasty as 
Compared to Suture. Surg Res Pract [Internet]. 2014;2014:1-5. Available from: https://doi.org/10.1155\%2F2014\%2F958634

20. Abu Ella A EAM. Comparing Skin Staples to Sutures for Fixing Mesh in Tension Free Hernioplasty. Med J Cairo Univ. 2015;83(1):23-
6.

21. Spaziani Testa S, Di Cello P, Lo Bianco G. "All In One Mesh Hernioplasty" device for inguinal hernia repair. Results of 400 cases. Ann Ital Chir. 2018;89:438-42.

\section{HOW TO CITE}

Metwalli, A., Elshahidy, T., Orban, Y. All-in-One Technique versus Lichtenstein Technique for Inguinal Hernia Repair: Comparative Study. Zagazig University Medical Journal, xxx; x(xxx-xxx): -. doi: 10.21608/zumj.2021.55790.2067 